\title{
Surviving mothers and lost babies - burden of stillbirths and neonatal deaths among women with maternal near miss in eastern Ethiopia: a prospective cohort study
}

\author{
Abera Kenay Tura ${ }^{1,2}$, \\ Sicco Scherjon ${ }^{2}$, Jos van \\ Roosmalen ${ }^{3,4}$, Joost Zwart ${ }^{5}$, Jelle \\ Stekelenburg ${ }^{6,7}$, Thomas van den \\ Akker 3,4 \\ ${ }^{1}$ School of Nursing and Midwifery, College \\ of Health and Medical Sciences, Haramaya \\ University, Harar, Ethiopia \\ ${ }^{2}$ Department of Obstetrics and Gynecology, \\ University Medical Centre Groningen, \\ University of Groningen, Groningen, the \\ Netherlands \\ ${ }^{3}$ Department of Obstetrics and Gynecology, \\ Leiden University Medical Centre, Leiden, \\ the Netherlands \\ ${ }^{4}$ Athena Institute, Vrije Universiteit \\ Amsterdam, the Netherlands \\ ${ }^{5}$ Department of Obstetrics and Gynecology, \\ Deventer Ziekenhuis, Deventer, the \\ Netherlands \\ ${ }^{6}$ Department of Health Sciences, Global \\ Health, University Medical Centre \\ Groningen, University of Groningen, \\ Groningen, the Netherlands \\ ${ }^{7}$ Department of Obstetrics and Gynecology, \\ Leeuwarden Medical Centre, Leeuwarden, \\ the Netherlands
}

\section{Correspondence to:}

Abera Kenay Tura, PhD

School of Nursing and Midwifery

College of Health and Medical Sciences

Haramaya University

P.O. Box 235

Harar, Ethiopia

a.k.tura@umcg.nl
Background Although maternal near miss (MNM) is often considered a 'great save' because the woman survived life-threatening complications, these complications may have resulted in loss of a child or severe neonatal morbidity. The objective of this study was to assess proportion of perinatal mortality (stillbirths and early neonatal deaths) in a cohort of women with MNM in eastern Ethiopia. In addition, we compared perinatal outcomes among women who fulfilled the World Health Organization (WHO) and the sub-Saharan African (SSA) MNM criteria.

Methods In a prospective cohort design, women with potentially life-threatening conditions (PLTC) (severe postpartum hemorrhage, severe pre-(eclampsia), sepsis/severe systemic infection, and ruptured uterus) were identified every day from January 1st, 2016, to April 30th, 2017, and followed until discharge in the two main hospitals in Harar, Ethiopia. Maternal and perinatal outcomes were collected using both sets of criteria. Numbers and proportions of stillbirths and early neonatal deaths were computed and compared.

Results Of 1054 women admitted with PTLC during the study period, 594 women fulfilled any of the MNM criteria. After excluding near misses related to abortion, ectopic pregnancy or among undelivered women, 465 women were included, in whom 149 (32\%) perinatal deaths occurred: 132 (88.6\%) stillbirths and 17 (11.4\%) early neonatal deaths. In absolute numbers, the SSA criteria picked up more perinatal deaths compared to the WHO criteria, but the proportion of perinatal deaths was lower in SSA group compared to the WHO (149/465, 32\% vs $62 / 100,62 \%)$. Perinatal mortality was more likely among near misses with antepartum hemorrhage (adjusted odds ratio $(\mathrm{aOR})=4.81 ; 95 \%$ $\mathrm{CI}=1.76-13.20)$, grand multiparous women $(\mathrm{aOR}=4.31 ; 95 \%$ confidence interval $\mathrm{CI}=1.23-15.25$ ), and women fulfilling any of the WHO near miss criteria ( $\mathrm{aOR}=4.89 ; 95 \% \mathrm{CI}=2.17-10.99)$.

Conclusion WHO MNM criteria pick up fewer perinatal deaths, although perinatal mortality occurred in a larger proportion of women fulfilling the WHO MNM criteria compared to the SSA MNM criteria. As women with MNM have increased risk of perinatal deaths (in both definitions), a holistic care addressing the needs of the mother and baby should be considered in management of women with MNM. 
Despite the fact that in Ethiopia between 1900 and 2015 a two-third reduction of under-five mortality as part of the Millennium Development Goals was achieved, this was not accomplished for neonatal mortality [1-3]. Perinatal mortality (fetal loss from 28 weeks of gestation onwards) and early neonatal mortality (within 7 days after birth) remained among the highest in sub-Saharan Africa [1-5].

Maternal near miss (MNM) is increasingly applied as an indicator of quality of obstetric care, putting women who barely survived severe complications of pregnancy into focus [6]. The World Health Organization (WHO) suggested MNM criteria that were not always deemed suitable for use in low-income settings in sub-Saharan Africa [7,8], following which adapted "sub-Saharan African (SSA) MNM criteria have been suggested in a recent Delphi consensus study [9].

Although it is clear that complications leading to MNM also contribute to adverse perinatal outcomes, the magnitude of stillbirths and early neonatal deaths among women with MNM is largely unknown in low-resource settings $[6,10,11]$. In theory, addressing factors that contribute to maternal complications could also reduce adverse perinatal outcomes, and it is therefore important to quantify the association between MNM and perinatal mortality [12-15]. Moreover, although MNM is often considered a 'great save', quantifying this association will bring attention to women who, having survived a life-threatening complication themselves, will nonetheless still have to deal with the loss of a child and other adverse maternal outcomes [16-22].

Stillbirth is a silent tragedy, and in general, compared to maternal mortality, audited less frequently in health facilities in low-resource countries [23-26]. It is also possible that audit of perinatal mortality is sometimes forgotten if a woman's life that was in danger of a life- threatening complication, was saved while her baby's life was lost. The objective of this study was to assess proportion of stillbirths and early neonatal deaths among a cohort of women with MNM in eastern Ethiopia. Additionally, this paper compares stillbirths and early neonatal deaths among cohorts of women with MNM according to the adapted sub-Saharan African and the original WHO MNM criteria. Finally, we aimed to assess factors associated with adverse perinatal outcomes among women with MNM.

\section{METHODS}

\section{Study setting and period}

This study was conducted in Hiwot Fana Specialized University Hospital and Jugel Hospital in Harar, Ethiopia, from January 1st, 2016, to April 30th, 2017, as part of a larger study on MNM and pregnancy-related mortality [27]. In brief, during this 16-month period, all women admitted with potentially life-threatening conditions, PLTC (severe postpartum hemorrhage, severe pre-eclampsia, eclampsia, sepsis/severe systemic infection, and ruptured uterus) were identified on a daily basis by trained research assistants and followed until discharge [28]. Upon discharge, women fulfilling the adapted SSA MNM criteria were included [9]. MNM was defined as any woman who had severe obstetric complications according to the SSA MNM criteria.

\section{Data collection}

Data on sociodemographic characteristics (maternal age, booking for antenatal care, gravidity, parity, referral status), obstetric conditions (onset of labor, mode of delivery, gestational age at birth, number of fetus), obstetric complications (obstetric hemorrhage, hypertensive disorders, sepsis, anemia, admission to intensive care unit, and receiving of blood), perinatal characteristics (vital status at birth, birthweight, $5^{\text {th }}$ minute Apgar score, admission to the neonatal intensive care unit), and maternal and perinatal vital status at discharge were collected by trained research assistants.

\section{Data processing and analysis}

All women admitted to the participating hospitals during the study period constituted the source population. The study population consisted of all women with PLTC. The inclusion criteria were fulfilling MNM according to the sub-Saharan Africa MNM criteria [9]. Women with near misses related to abortion, ectopic pregnancy or were discharged before delivery were excluded from the analysis. Data were entered using EpiData v3.1 (www.epidata.dk) and analyzed using Stata v.13 software (StataCorp Inc, College Station, TX, USA). The main outcome of study was perinatal mortality: stillbirths and early neonatal deaths. Independent variables consist of maternal conditions and complications, institutional factors (referral status, admission dates, booking for antenatal care), and fetal conditions (birthweight, admission to neo- 
natal intensive care unit, Apgar score and number of fetus). Bivariate and multivariate logistic regression were used to determine factors associated with perinatal mortality. Variables with $P$-value $\leq 0.25$ in the bivariate analysis were retained for multivariate analysis. Significance level was set at $P$-value of $<0.05$.

\section{Ethics}

This study was conducted as part of a larger prospective study of severe maternal outcomes (maternal near miss and mortality) in eastern Ethiopia [27]. The study protocol was reviewed and approved by the Institutional Health Research Ethics Review Committee of College of Health and Medical Sciences, Haramaya University, Ethiopia (Ref N: C/A/R/D/01/1681/16).

\section{RESULTS}

During the study period, of 8002 women admitted to both hospitals during pregnancy and childbirth, 7929 deliveries (including 7404 livebirths and 598 stillbirths) and 1054 women with PLTC were registered. The SSA MNM criteria identified 594 women with MNM while the WHO MNM criteria identified 128. After exclusion of women with near misses related to abortion, ectopic pregnancy, undelivered women, or unknown fetal status at discharge, 465 women with MNM were included in the analysis (Figure 1).

The mean age of women with MNM $(n=465)$ was $25.3( \pm 6.2)$ years ranging from $15-45$. More than half $(n=282 ; 61 \%)$ were referred from other facilities and more than two-third $(n=316 ; 68 \%)$ were not booked for antenatal consultation. One hundred eighty-one (38.9\%) women gave birth by cesarean sec-

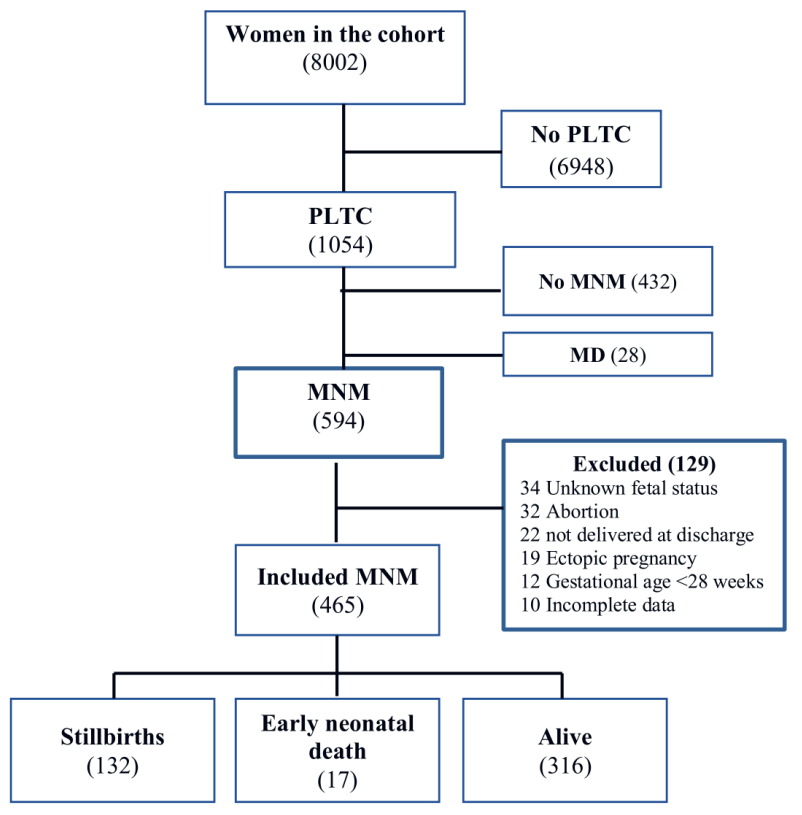

Figure 1. Flowchart describing the inclusion process in the study. PLTC - potentially life-threatening conditions, SMO severe maternal outcomes, MNM - maternal near miss. tion and hysterectomy was done in 44 (9.5\%). With regard to complications, 231 (49.7\%) had hypertensive disorders, 157 (33.8\%) obstetric hemorrhage, and 109 (23.4\%) sepsis. About 141 (30.3\%) were anemic ( $\mathrm{Hb}<7 \mathrm{gm} / \mathrm{dl})$ and 166 (35.7\%) received at least one unit of blood (Table 1). A total of 149 perinatal deaths (132 stillbirths and 17 early neonatal deaths were registered), resulting in a stillbirth and early neonatal mortality rate of 284 and 36.6 per 1000 births respectively. The perinatal mortality rate was 320 per 1000 births in the SSA group and 620 per 1000 births in the WHO MNM group. The proportion of still births was 244 and 75 per 1000 births among women with PLTC and all women admitted to the hospital during the study period respectively. Thus, proportion of stillbirths per 1000 births was highest in the cohort of women with MNM $(n=284)$.

Compared to the WHO MNM criteria, the SSA criteria picked up more perinatal deaths (149 vs 62) while the proportion of perinatal deaths was higher in the WHO group (62\% vs 32\%). Additionally, admission to neonatal intensive care unit, stillbirths and early neonatal deaths were more common among women in the WHO criteria compared to the SSA MNM group. Birthweight and $5^{\text {th }}$ minute Apgar score did not differ between the two groups (Table 2).

\section{Factors associated with perinatal mortality}

Factors associated with perinatal mortality in the study participants $(n=465)$ are summarized in Table 3. Perinatal death was more likely among women who had antepartum hemorrhage ( $\mathrm{aOR}=4.81 ; 95 \%$ $\mathrm{CI}=1.76-13.20)$, grand multiparous women ( $\mathrm{aOR}=4.31 ; 95 \% \mathrm{CI}=1.23-15.25)$, and women who fulfilled WHO MNM criteria ( $\mathrm{aOR}=4.89 ; 95 \% \mathrm{CI}=2.17-10.99)$. No statistically significant association was observed between perinatal mortality and referral status, gestational age, and birthweight (Table 3).

\section{DISCUSSION}

Our findings indicate the high burden of adverse perinatal outcomes (stillbirths and neonatal deaths) among women with MNM. More than one in three of women with MNM went home with a dead baby. 
Table 1. Sociodemographic characteristics of study participants with and without adverse perinatal outcomes

\begin{tabular}{|c|c|c|c|}
\hline \multirow{2}{*}{ Variables } & & \multicolumn{2}{|c|}{ Adverse PERINATAL OUTCOMES } \\
\hline & & Yes $(n=149), \%$ & No $(n=316), \%$ \\
\hline \multicolumn{4}{|l|}{ Maternal characteristics: } \\
\hline \multirow[t]{3}{*}{ Age (years) } & $<20$ & $15(10.3) *$ & $50(15.8)$ \\
\hline & $20-35$ & $104(71.2)$ & $232(73.4)$ \\
\hline & $>35$ & $27(18.5)$ & $34(10.8)$ \\
\hline \multirow[t]{2}{*}{ Referred from other facility } & No & $47(32.0)+$ & $133(42.2) \ddagger$ \\
\hline & Yes & $100(68.0)$ & $182(57.8)$ \\
\hline \multirow{2}{*}{ Received antenatal care: } & Yes§ & $47(31.5)$ & $102(32.3)$ \\
\hline & No & $102(68.5)$ & $214(67.7)$ \\
\hline \multirow[t]{2}{*}{ Gravida } & 1 & $34(23.1) 2$ & $137(43.6) 2$ \\
\hline & $\geq 2$ & $113(76.9)$ & $177(56.4)$ \\
\hline \multirow[t]{2}{*}{ Mode of delivery } & Vaginal & $79(53.0)$ & 205 (64.9) \\
\hline & Cesareanll & $70(47)$ & $111(35.1)$ \\
\hline \multicolumn{4}{|l|}{ Obstetric complications: } \\
\hline \multirow[t]{2}{*}{ Obstetric hemorrhage } & Yes & $85(57.0)$ & $72(22.8)$ \\
\hline & No & $64(43.0)$ & $244(77.2)$ \\
\hline \multirow[t]{2}{*}{ Hypertensive disorders } & Yes & $47(31.5)$ & $184(58.2)$ \\
\hline & No & $102(68.5)$ & $132(41.8)$ \\
\hline \multirow[t]{2}{*}{ Sepsis } & Yes & $19(12.8)$ & $90(28.5)$ \\
\hline & No & $130(87.2)$ & $226(71.5)$ \\
\hline \multirow[t]{2}{*}{ Anemia } & Yes & $63(42.3)$ & $78(24.7)$ \\
\hline & No & $86(57.7)$ & $238(75.3)$ \\
\hline \multirow[t]{2}{*}{ Received blood } & Yes & $81(54.4)$ & $85(26.9)$ \\
\hline & No & $68(45.6)$ & $231(73.1)$ \\
\hline
\end{tabular}

*Missing information $(\mathrm{n}=3)$.

+Missing information $(\mathrm{n}=2)$.

\$Missing information $(\mathrm{n}=1)$.

$\S$ At least one antenatal care.

\|Includes laparotomy
This highlights the importance of close monitoring of fetal conditions in those women. Adverse perinatal outcomes were more likely among grand multiparous women and women with antepartum hemorrhage. Given the fact that the WHO MNM tool is based on more severe clinical criteria identifying advanced disease with organ dysfunction, it is self-evident that perinatal outcomes in this group were worse (62 per 1000 births) compared to the SSA MNM group (32 per 1000 births).

The stillbirth rate of 284 per 1000 births is unacceptably high. This is almost twice as high as findings from a general population in public health facilities in southern Ethiopia $(n=183)$ and more than ten times higher than the average stillbirth rate ( 25 to 31 per 1000 births) in the general population in low-income settings of southern Africa and Asia [29,30].

The stillbirth rate (284) in our study was found to be higher than in a cohort of women with MNM in Brazil (195 per 1000 births) [31]. The fact that stillbirths in our SSA MNM cohort were even higher than in the Brazilian cohort defined by the WHO MNM criteria shows the high burden of stillbirths in our setting, which may be related to differences in the quality of intrapartum care.

Although the proportion of stillbirths was higher (58\%) among women fulfilling the WHO MNM criteria, the rate in the SSA group (28.4\%) indicates that women with MNM according to SSA criteria are still in an advanced stage of disease. The common pathways to severe maternal and perinatal outcomes are potential areas of intervention for addressing the needs of both women and newborns [6]. Factors associated with adverse perinatal outcomes in this study (antepartum hemorrhage, lack of prenatal care) were comparable with findings from previous studies in Uganda [32], Nigeria [33], the Gambia [34], and Brazil [35]. We found that perinatal deaths were higher in absolute numbers among women in the SSA MNM group. This highlights the importance of considering the use of the SSA MNM criteria for more robust audit if better maternal and perinatal outcomes are to be achieved [27]. The strength of this study is the use of prospective case identification and large sample size. Some limitations should also be considered. First, this study was not population-based and MNM women with adverse perinatal outcomes

Table 2. Fetal outcomes among women with and without the WHO MNM criteria

\begin{tabular}{|c|c|c|c|c|c|}
\hline \multirow{2}{*}{ Variables } & & \multicolumn{2}{|c|}{ FuLFILED WHO MNM CRITERIA } & \multirow{2}{*}{ TotAL } & \multirow[b]{2}{*}{$\boldsymbol{P}$-value $\dagger$} \\
\hline & & Yes* $(n=100, \%)$ & No $(n=365, \%)$ & & \\
\hline \multirow[t]{2}{*}{ Fetal vital status at birth } & Alive & $42(42.0)$ & $291(79.7)$ & $333(71.6)$ & \multirow{2}{*}{$<0.001$} \\
\hline & Stillbirths & $58(58.0)$ & $74(20.3)$ & $132(28.4)$ & \\
\hline \multirow[t]{3}{*}{ Birth weight (grams) } & $<1500$ & $8(8.0)$ & $19(5.2)$ & $27(5.8)$ & \multirow{3}{*}{0.476} \\
\hline & $1500-2400$ & $16(16.0)$ & $70(19.2)$ & $86(18.5)$ & \\
\hline & $\geq 2500$ & $76(76.0)$ & $276(75.6)$ & $352(75.7)$ & \\
\hline \multirow[t]{2}{*}{$5^{\text {th }}$ minute Apgar score } & $<7$ & $4(4.0)$ & $17(4.7)$ & $21(4.5)$ & \multirow{2}{*}{0.779} \\
\hline & $\geq 7$ & $96(96.0)$ & $348(95.3)$ & $444(95.5)$ & \\
\hline \multirow[t]{2}{*}{ Admitted to neonatal intensive care unit } & No & $96(96.0)$ & $325(89.0)$ & $421(90.5)$ & \multirow{2}{*}{0.035} \\
\hline & Yes & $4(4.0)$ & $40(11.0)$ & $44(9.5)$ & \\
\hline \multirow[t]{2}{*}{ Neonatal outcome at discharge } & Alive & $38(38.0)$ & $278(76.2)$ & $316(68.0)$ & \multirow{2}{*}{$<0.001$} \\
\hline & Dead & $62(62.0)$ & $87(23.8)$ & $149(32.0)$ & \\
\hline
\end{tabular}

WHO - World Health Organization, MNM - maternal near miss

*Fulfil the sub-Saharan Africa criteria.

$\dagger \chi 2$ test. 
Table 3. Factors associated with perinatal mortality among women with MNM in eastern Ethiopia

\begin{tabular}{|c|c|c|c|c|}
\hline \multirow{2}{*}{ Variabies } & & \multicolumn{3}{|c|}{ Perinatal deaths } \\
\hline & & № & cOR & aOR \\
\hline \multirow[t]{2}{*}{ Ante partum hemorrhage } & No & 308 & Ref & Ref \\
\hline & Yes & 157 & $3.93(1.77-8.74)$ & $4.81(1.76-13.20)$ \\
\hline \multirow[t]{3}{*}{ Parity* } & 0 & 126 & Ref & Ref \\
\hline & $1-4$ & 208 & $0.93(0.56-1.55)$ & \\
\hline & $\geq 5$ & 127 & $3.08(1.81-5.24)$ & $4.31(1.23-15.25)$ \\
\hline \multirow[t]{2}{*}{ Referred from other facilities $\dagger$} & No & 180 & Ref & \\
\hline & Yes & 282 & $1.55(1.03-2.35)$ & \\
\hline \multirow[t]{2}{*}{ Gestational age } & Pre-term Term( $\geq 37$ weeks $)$ & 147 & Ref & \\
\hline & & 318 & $0.45(.0 .30-0.68)$ & \\
\hline \multirow[t]{3}{*}{ Birthweight (gram) } & $\geq 2500$ & 352 & Ref & \\
\hline & $1500-2400$ & 86 & $1.30(0.79-2.15)$ & \\
\hline & $<1500$ & 27 & $8.94(3.51-22.82)$ & \\
\hline \multirow[t]{2}{*}{ Fulfilled WHO MNM criteria } & No & 365 & Ref & Ref \\
\hline & Yes & 100 & $5.21(3.26-8.34)$ & $4.89(2.17-10.99)$ \\
\hline
\end{tabular}

cOR - crude odds ratio, aOR - adjusted odds ratio, Ref - reference group, WHO - World Health Organization, MNM - maternal near miss

*Missing information $(\mathrm{n}=4)$.

$\dagger$ Missing information $(n=3)$.

who could not reach hospital are missed. Second, follow-up was limited to only seven days or until discharge. Some perinatal deaths and MNM events may have occurred after discharge.

\section{CONCLUSIONS}

Behind the rescued life of a woman with MNM, often lies the silent tragedy of stillbirths and neonatal deaths [23-26]. Although these women survived the life-threatening complications, they have to be supported to deal with loss of baby since burden of stillbirths and early neonatal deaths is more common in women with MNM. Compared to the WHO MNM criteria, the SSA MNM criteria is a better choice for conducting robust perinatal audit for improving perinatal care and survival. The high stillbirth rate in this cohort highlights the importance conducting a thorough audit of perinatal deaths to identify opportunities to improve these outcomes in the future.

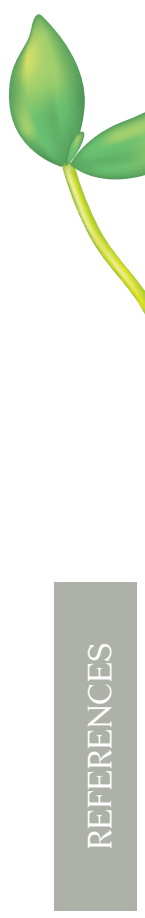

Acknowledgments: We thank Nuffic for financial support of the study. We want to thank all the research assistants and hospital administrators who were helpful during the study.

Funding: This study was funded by the Netherlands Organization for International Cooperation in Higher Education (Nuffic) as part of a PhD study to AKT. The organization has no role in the design of the study, collection, analysis or interpretation of data or the decision to submit for publication.

Authorship contributions: AKT, SS, and JZ conceived the study. AKT analyzed the data. AKT drafted the manuscript, which was revised by SS, JvR, JZ, JS, TvdA. Overall supervision: SS, JvR, JZ, JS, TvdA. All authors approved the final version for submission.

Competing interests: The authors completed the ICMJE Unified Competing Interest form (available upon request from the corresponding author), and declare no conflicts of interest.

2 Berhan Y, Berhan A. Perinatal mortality trends in Ethiopia. Ethiop J Health Sci. 2014;24:29-40. Medline:25489181 doi:10.4314/ejhs.v24i0.4S

3 Assefa Y, Damme WV, Williams OD, Hill PS. Successes and challenges of the millennium development goals in Ethiopia: lessons for the sustainable development goals. BMJ Glob Health. 2017;2:e000318. Medline:29081999 doi:10.1136/ bmjgh-2017-000318

4 Bayou G, Berhan Y. Perinatal mortality and associated risk factors: a case control study. Ethiop J Health Sci. 2012;22:15362. Medline:23209349 
5 World Health Organization. Neonatal and perinatal mortality: country, regional and global estimates. WHO: Geneva; 2006.

6 World Health Organization. Evaluating the quality of care for severe pregnancy complications: the WHO near-miss approach for maternal health. WHO: Geneva; 2011.

7 Nelissen E, Mduma E, Broerse J, Ersdal H, Evjen-Olsen B, van Roosmalen J, et al. Applicability of the WHO maternal near miss criteria in a low-resource setting. PLoS One. 2013;8:e61248. Medline:23613821 doi:10.1371/journal.pone.0061248

8 van den Akker T, Beltman J, Leyten J, Mwagomba B, Meguid T, Stekelenburg J, et al. The WHO maternal near miss approach: consequences at Malawian District level. PLoS One. 2013;8:e54805. Medline:23372770 doi:10.1371/journal. pone.0054805

9 Tura AK, Stekelenburg J, Scherjon SA, Zwart J, van den Akker T, van Roosmalen J, et al. Adaptation of the WHO maternal near miss tool for use in sub-Saharan Africa: an International Delphi study. BMC Pregnancy Childbirth. 2017;17:445. Medline:29284433 doi:10.1186/s12884-017-1640-x

10 Goba GK, Tsegay H, Gebregergs GB, Mitiku M, Kim KA, Alemayehu M. A facility-based study of factors associated with perinatal mortality in Tigray, northern Ethiopia. Int J Gynaecol Obstet. 2018;141:113-9. Medline:29318613 doi:10.1002/ ijgo. 12438

11 Simsek A, Uludag S, Benian A, Tuten A, Oncul M, Acikgoz SA. The effect of life threatening conditions of women on perinatal outcome. HJOG. 2016;15:46-52.

12 Anggondowati T, El-Mohandes AA, Qomariyah SN, Kiely M, Ryon JJ, Gipson RF, et al. Maternal characteristics and obstetrical complications impact neonatal outcomes in Indonesia: a prospective study. BMC Pregnancy Childbirth. 2017;17:100. Medline:28351384 doi:10.1186/s12884-017-1280-1

13 Adisasmita A, Smith CV, El-Mohandes AA, Deviany PE, Ryon JJ, Kiely M, et al. Maternal characteristics and clinical diagnoses influence obstetrical outcomes in Indonesia. Matern Child Health J. 2015;19:1624-33. Medline:25656716 doi:10.1007/s10995-015-1673-6

14 Bener A, Al-Nufal M, Vachhani PJ, Ali AI, Samson N, Saleh NM. Maternal complications and neonatal outcome in Arab women of a fast developing country. J Family Community Med. 2013;20:27-34. Medline:23723728 doi:10.4103/22308229.108181

15 Weiner R, Ronsmans C, Dorman E, Jilo H, Muhoro A, Shulman C. Labour complications remain the most important risk factors for perinatal mortality in rural Kenya. Bull World Health Organ. 2003;81:561-6. Medline:14576887

16 Moreira DDS, Gubert MB. Healthcare and sociodemographic conditions related to severe maternal morbidity in a state representative population, Federal District, Brazil: A cross-sectional study. PLoS One. 2017;12:e0180849. Medline:28771494 doi:10.1371/journal.pone.0180849

17 Ilboudo PG, Russell S, D'Exelle B. The long term economic impact of severe obstetric complications for women and their children in Burkina Faso. PLoS One. 2013;8:e80010. Medline:24224028 doi:10.1371/journal.pone.0080010

18 Storeng KT, Murray SF, Akoum MS, Ouattara F, Filippi V. Beyond body counts: a qualitative study of lives and loss in Burkina Faso after 'near-miss' obstetric complications. Soc Sci Med. 2010;71:1749-56. Medline:20541307 doi:10.1016/j. socscimed.2010.03.056

19 Storeng KT, Baggaley RF, Ganaba R, Ouattara F, Akoum MS, Filippi V. Paying the price: the cost and consequences of emergency obstetric care in Burkina Faso. Soc Sci Med. 2008;66:545-57. Medline:18061325 doi:10.1016/j. socscimed.2007.10.001

20 Kilpatrick SJ, Abreo A, Gould J, Greene N, Main EK. Confirmed severe maternal morbidity is associated with high rate of preterm delivery. Am J Obstet Gynecol. 2016;215:233.e1-7. Medline:26899903 doi:10.1016/j.ajog.2016.02.026

21 Mbalinda SN, Nakimuli A, Nakubulwa S, Kakaire O, Osinde MO, Kakande N, et al. Male partners' perceptions of maternal near miss obstetric morbidity experienced by their spouses. Reprod Health. 2015;12:23. Medline:25884387 doi:10.1186/s12978-015-0011-1

22 Kaye DK, Kakaire O, Nakimuli A, Mbalinda SN, Osinde MO, Kakande N. Survivors' understanding of vulnerability and resilience to maternal near-miss obstetric events in Uganda. Int J Gynaecol Obstet. 2014;127:265-8. Medline:25087177 doi:10.1016/j.ijgo.2014.05.019

23 Scott J. Stillbirths: breaking the silence of a hidden grief. Lancet. 2011;377:1386-8. Medline:21496914 doi:10.1016/ S0140-6736(11)60107-4

24 Kelley MC, Trinidad SB. Silent loss and the clinical encounter: Parents' and physicians' experiences of stillbirth-a qualitative analysis. BMC Pregnancy Childbirth. 2012;12:137. Medline:23181615 doi:10.1186/1471-2393-12-137

25 Kiguli J, Namusoko S, Kerber K, Peterson S, Waiswa P. Weeping in silence: community experiences of stillbirths in rural eastern Uganda. Glob Health Action. 2015;8:24011. Medline:25843493 doi:10.3402/gha.v8.24011

26 Basile ML, Thorsteinsson EB. Parents' evaluation of support in Australian hospitals following stillbirth. PeerJ. 2015;3:e1049. Medline:26137430 doi:10.7717/peerj.1049

27 Tura AK, Zwart J, van Roosmalen J, Stekelenburg J, van den Akker T, Scherjon S. Severe maternal outcomes in eastern Ethiopia: Application of the adapted maternal near miss tool. PLoS One. 2018;13:e0207350. Medline:30427926 doi:10.1371/journal.pone.0207350

28 Say L, Souza JP, Pattinson RC. WHO working group on Maternal Mortality and Morbidity classifications. Maternal near miss-towards a standard tool for monitoring quality of maternal health care. Best Pract Res Clin Obstet Gynaecol. 2009;23:287-96. Medline:19303368 doi:10.1016/j.bpobgyn.2009.01.007

29 Goldenberg RL, McClure EM, Bann CM. The relationship of intrapartum and antepartum stillbirth rates to measures of obstetric care in developed and developing countries. Acta Obstet Gynecol Scand. 2007;86:1303-9. Medline:17963057 doi:10.1080/00016340701644876 
30 Tsegaye B, Kassa A. Prevalence of adverse birth outcome and associated factors among women who delivered in Hawassa town governmental health institutions, south Ethiopia, in 2017. Reprod Health. 2018;15:193. Medline:30477512 doi:10.1186/s12978-018-0631-3

31 Oliveira LC, Costa AA. Fetal and neonatal deaths among cases of maternal near miss. Rev Assoc Med Bras. 2013;59:48794. Medline:24080346 doi:10.1016/j.ramb.2013.08.004

32 Cham M, Sundby J, Vangen S. Fetal outcome in severe maternal morbidity: too many stillbirths. Acta Obstet Gynecol Scand. 2009;88:343-9. Medline:19172420 doi:10.1080/00016340902730318

33 Olagbuji BN, Ezeanochie MC, Igbaruma S, Okoigi SO, Ande AB. Stillbirth in cases of severe acute maternal morbidity. Int J Gynaecol Obstet. 2012;119:53-6. Medline:22877837 doi:10.1016/j.ijgo.2012.05.032

34 Zanardi DM, Parpinelli MA, Haddad SM, Costa ML, Sousa MH, Leite DFB, et al. Adverse perinatal outcomes are associated with severe maternal morbidity and mortality: evidence from a national multicentre cross-sectional study. Arch Gynecol Obstet. 2019;299:645-54. Medline:30539385 doi:10.1007/s00404-018-5004-1

35 Nakimuli A, Mbalinda SN, Nabirye RC, Kakaire O, Nakubulwa S, Osinde MO, et al. Still births, neonatal deaths and neonatal near miss cases attributable to severe obstetric complications: a prospective cohort study in two referral hospitals in Uganda. BMC Pediatr. 2015;15:44. Medline:25928880 doi:10.1186/s12887-015-0362-3 